\title{
Saturated and unsaturated stability analysis of slope subjected to rainfall infiltration
}

\author{
Nurly Gofar ${ }^{1, *}$ and Harianto Rahardjo ${ }^{1}$ \\ ${ }^{1}$ School of Civil Engineering, Nanyang Technological University, 50 Nanyang Avenue, 639798 Singapore
}

\begin{abstract}
This paper presents results of saturated and unsaturated stability analysis of typical residual slopes subjected to rainfall infiltration corresponds to 50 years rainfall return period. The slope angles considered were $45^{\circ}$ and $70^{\circ}$. The saturated stability analyses were carried out for original and critical ground water level commonly considered by practicing engineer. The analyses were conducted using limit equilibrium method. Unsaturated stability analyses used combination of coupled stress-pore-water pressure analysis to evaluate the effect of rainfall infiltration on the deformation and transient pore-water pressure on slope stability. Slope stability analyses were performed at some times during and after rainfall infiltration. Results show that the critical condition for slope made by sandy material was at the end of rainfall while for clayey material was at some specified times after the rainfall ceased. Unsaturated stability analysis on sandy soil gives higher factor of safety because the soil never reached saturation. Transient analysis using unsaturated soil concept could predict more critical condition of delayed failure of slopes made up of clayey soil.
\end{abstract}

\section{Submitting the manuscript}

Many residual slopes in tropical region with very deep ground water table stand at a steep angle. This is due to the strength of unsaturated soil which is governed by two independent stress-state variables: matric suction (negative pore-water pressure) and net normal stress [1]. The stability of the slope could be disturbed by rainfall infiltration through the slope surface. Rainwater infiltration into the unsaturated soil decreases the matric suction, hence affecting the shear strength properties and thus the probability of slope failure. Furthermore, heavy downpour may cause raising ground water level (GWL), development of a perched water table and positive porewater pressure in the soil slope. This condition will further decrease the shear strength of soil and eventually make the slope increasingly susceptible to failure.

Although the contribution of soil suction to the shear strength of unsaturated soils has been increasingly accepted, the inclusion of soil suction in the long term slope stability analysis is still not a common practice [2]. Practicing engineers found that it is impractical and risky to perform such rigorous and time consuming analysis. Conventional slope stability analysis is usually performed for saturated condition, hence the effect of suction is not considered. Effect of rainfall is considered by assuming raise in GWL to the assumed most critical condition. In Singapore, the most critical condition is considered by bringing up the actual GWL below crest by $1 \mathrm{~m}$, positioning the GWL at ground surface (GS) at the toe and connecting the two lines by a straight line.
This practice is based on the ground water fluctuation in Singapore which is about $1 \mathrm{~m} \mathrm{[3].}$

The stability of slopes is generally assessed using limit equilibrium method where Factor of Safety (FoS) is estimated as the ratio of the soil strength and driving stress acting along the potential failure surface. Many computer programs for slope stability analysis (e.g. SLOPE/W) were developed based on limit equilibrium approach and are available in the market. The limit equilibrium method treats the soils as rigid plastic materials. The method does not take into account the effect of slope deformation induced by stress. Hence, finite element software (e.g. FLAC, PLAXIS, SIGMA/W) have been utilized by practicing engineers and researchers to assess the stability of the slope through deformation analysis and the FoS was obtained as strength reduction factor [4-6]. Similarly, pore-water pressure variation induced by rainfall infiltration is not considered in the current practice using limit equilibrium method. Rainfall infiltration influences the strength; thus soil resistance is not constant throughout the process of rainfall infiltration. The reduction of shear strength due to wetting trigger the shear deformation of slopes [7]. The effect of strength and modulus reduction due to rainfall infiltration could be considered if the concept of unsaturated soil was applied in the analysis [1].

Both effect of stress and pore water pressure should be incorporated in the slope stability analysis. The analysis should be carried out for pore-water pressure condition during and after rainfall because researchers [8-9] have suggested that delayed failure could occur in slope made of clayey soil due to low permeability.

Corresponding author:nurlygofar@ntu.edu.sg 
This study was aimed to show that, for some conditions, analysis using unsaturated soil concept could predict more critical condition to the slope. In this study, the transient analyses were performed using coupled stress - pore-water pressure analysis using SIGMA/W [10] to obtain deformation and pore-water pressure conditions at different times during and after a rainfall event. Slope stability analyses were performed using SLOPE/W [11] at some specified times during and after the rainfall event. FoS obtained from slope stability analysis were plotted with respect to time and compared to the factor of safety obtained from conventional analysis considering the original GWL and the assumed critical GWL.

\section{Properties of unsaturated soil}

Limit equilibrium method is widely used in practice for slope stability analysis due to its reliability for most practical cases. The FoS of a slope is assessed by the ratio of the resistance force (quantified by the shear strength of the soil) to the mobilized force. Thus, the shear strength of soil is an important parameter for the slope stability analysis. The shear strength is derived from Mohr-Coulomb failure criterion and Terzaghi's effective stress concept, defined as:

$$
\tau_{f f}=c^{\prime}+\left(\sigma_{n}-\mu_{w}\right) \tan \phi^{\prime}
$$

where, $\tau_{f f}$ is the shear stress at failure; $c$ ' is the effective cohesion and $\phi$ 'is the effective angle of shearing resistance with respect to net normal stress $\left(\sigma_{n}-\mu_{w}\right)$.

For unsaturated soil, the water phase occupies only parts of the pore volume, while the rest is filled by air. Therefore, the main difference between shear strength of saturated soils and unsaturated soils is the definition for effective normal stress. A practical formulation for shear strength of unsaturated soil was proposed by [12]:

$$
\tau_{f f}=c^{\prime}+\left(\sigma_{n}-u_{a}\right)_{f} \tan \phi^{\prime}+\left(u_{a}-u_{w}\right)_{f} \tan \phi^{b}
$$

Where $\phi^{b}$ is the angle of frictional resistance with respect to matric suction $\left(\mu_{a}-\mu_{w}\right)$. Eq. (2) shows that the shear strength of an unsaturated soil has a close relationship with pore water pressure $\left(\mu_{w}\right)$ and pore air pressure $\left(\mu_{a}\right)$ because the shear strength is governed by the wetted contact area of the soil particles. Fig. 1 shows Mohr-Coulomb representation of shear strength of unsaturated soil.

The ratio between the pore water and the pore air pressures is controlled by the amount of water in soil (water content) [13]. A fundamental property that relates the suction and water holding ability of soil is the soil water characteristic curve (SWCC) as shown in Fig 2. The SWCC curve can be divided into three regions i.e. boundary effect zone, transition zone and residual zone. The rate of desaturation with respect to an increase in matric suction is the greatest in the transition zone which occurs between the air-entry point (AEV) and the residual suction $\left(\theta_{r}\right)$. The variation of shear strength with respect to matric suction in the transition zone significant $[1,7]$, hence the definition of $\mathrm{AEV}$ and residual matric suction is very crucial in the estimation of shear strength of unsaturated soil. Theoretically, the unsaturated soil with matric suction less than AEV is deemed to behave like a saturated soil. Thus, the $\phi^{b}$ under this condition can be approximated as equal to $\phi$ ' [7] Beyond the AEV, the $\phi^{b}$ of fine grained soil decreases to a lower value. When laboratory data is not available $\phi^{b}$ between $0.5 \phi$, and $\phi$ ' could be used for analysis [14].



Fig. 1. Extended Mohr-Coulomb failure envelope for unsaturated soils [1]

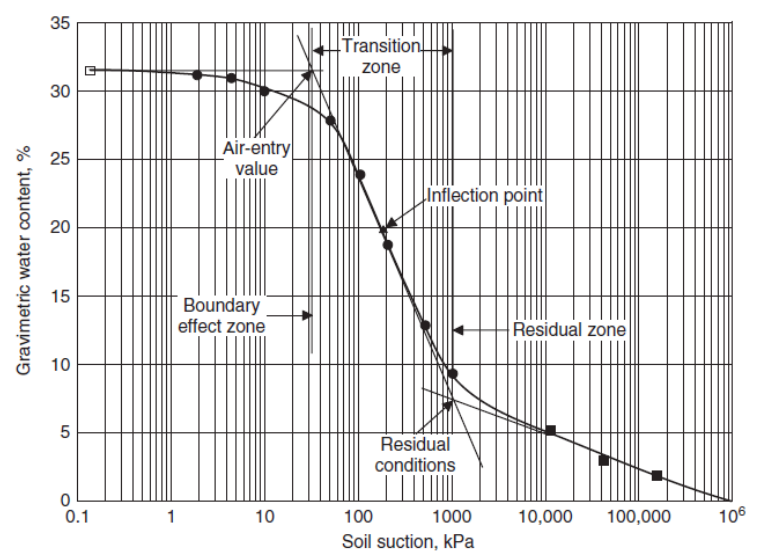

Fig. 2. Typical SWCC curve [1]

The elasticity form of the volumetric strain constitutive relationship for an unsaturated soil under plain strain condition as presented in [1] as:

$$
d \varepsilon_{v}=\frac{2(1+\mu)(1-2 \mu)}{E} d\left(\sigma_{a v e}-u_{a}\right)+2 \frac{1+\mu}{H} d\left(\mu_{a}-\mu_{w}\right)
$$

where $d \varepsilon_{v}$ is volumetric strain increment, $d\left(\sigma_{a v e}-\mu_{a}\right)$ and $d\left(\mu_{a}-\mu_{w}\right)$ are the net normal stress and matric suction increment respectively. $E$ is the elastic modulus with respect to change in net normal stress while $H$ is the elastic modulus with respect to change in suction. The relationship between $E$ and $H$ for saturated soil in given in the following equation whereby $v$ is the Poisson's ratio [1]:

$$
E / H=(1-2 v)
$$


The effect of suction on the $E / H$ ratio was studied by [15] for Bukit Timah Granite in Singapore. The relation was obtained in this study:

$$
E / H=(1-2 v)\left[1-0.003\left(\mu_{a}-\mu_{w}\right)\right]
$$

\section{Methodology}

\subsection{Slope model and analysis}

In order to investigate the effect of infiltration on slope stability and to compare the results of unsaturated slope stability analysis with those of conventional analysis, a typical slope was selected in this study as shown in Fig. 3. Two slope angles and two types of soil were considered. The slope angles $(\alpha)$ were $45^{\circ}$ and $70^{\circ}$ while the soils were sandy and clayey soils represented by their shear strength, elastic properties, SWCC and permeability function. The slope was $4 \mathrm{~m}$ high. Slope of $45^{\circ}$ was selected because a 1:1 slope is considered as stable for residual soil slope in Singapore, while slope of $70^{\circ}$ is the maximum inclination of ground to be analyzed as a slope. The initial ground water level (GWL) condition is as shown in Fig. 3.

Conventional (saturated) stability analysis was carried out using SLOPE/W with $\phi^{b}$ equal to zero. The analyses were performed for the original GWL and critical condition by raising the GWL below crest by $1 \mathrm{~m}$ and the GWL at the toe side coincide with ground surface (GS).

The effect of rainfall infiltration on the slope stability was evaluated by applying a rainfall of $22 \mathrm{~mm} / \mathrm{h}$ with duration corresponding to 50 year return period (RP) in Singapore i.e. 8 hour $[16,17]$. The infiltration process of the rainwater into the soil was analyzed using stressdeformation finite element software SIGMA/W. The SIGMA/W is capable of performing seepage analysis coupled with stress/deformation analysis. Slope stability analyses were carried out using SLOPE/W for several conditions during and after rainfall.

The model adopted in this study was twodimensional plane strain. The boundary conditions applied to the finite element analysis are illustrated in Fig. 3. The distance between the slope and the sides of the slope model was set to three times the height of the slope to eliminate the effect of boundary conditions. No flow boundary were simulated by assigning a nodal flux $Q$ equal to zero at the bottom and sides of the slope model above GWL. A constant total head $h_{w}$ was applied on each side boundary below GWL. Rainfall was applied to the slope as flux boundary $q$. Ponding was not allowed to occur on the slope surface. This meant that if a flux greater than the permeability of the soil was applied, the seepage model will not allow pore water pressure greater than $0 \mathrm{kPa}$ to built-up. This simulates the actual condition whereby the excess rainwater on the slope would become surface flow or runoff. The initial condition of the slope was taken based on the position of the initial GWL as in Fig. 3. Unsaturated slope stability analyses were performed for seepage conditions during with an interval of $2 \mathrm{~h}$ and after rainfall with interval of 1 day.

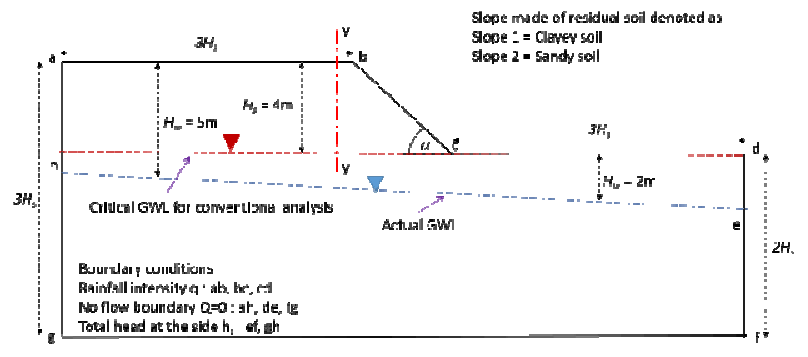

Fig. 3. Slope geometry and boundary conditions adopted in this study

\subsection{Material properties}

The slope was made of residual soil. Two types of soil were selected to represent sandy and clayey soils. The typical shear strength properties of Singapore residual soils as shown in Table 1 were selected for limit equilibrium analysis using SLOPE/W. The properties of clayey soil was based on [18] while for sandy soil, typical values were adopted.

Table 1. Soil properties

\begin{tabular}{|c|c|c|c|c|c|c|}
\hline Soil & $\begin{array}{c}\gamma_{b} \\
\left(k N / m^{3}\right)\end{array}$ & $\begin{array}{c}\mathbf{c}^{\prime} \\
(\mathbf{k P a})\end{array}$ & $\phi^{\prime}$ & $\phi^{\mathbf{b}}$ & $\begin{array}{c}E \\
(\mathrm{kPa})\end{array}$ & $v$ \\
\hline Clayey & 20 & 10 & 26 & 17 & 10,000 & 0.40 \\
\hline Sandy & 20 & 5 & 33 & 23 & 15,000 & 0.33 \\
\hline
\end{tabular}

SWCC and permeability functions are two primary soil properties used in the deformation-seepage analysis. The SWCC and permeability function used in this study was based on [18] to represent clayey $\left(f_{100,-6}\right)$ and sandy soil $\left(f_{10,-4}\right)$. The SWCC was plotted based on Fredlund and Xing (1994) with $c(\psi)=1$ [19] while the permeability function was based on [20]. The SWCC and permeability function of the residual soil is shown in Fig. 4. The SWCC and permeability function parameters adopted in this study are given in Table 2 .


Fig. 4. SWCCs and permeability functions used in this study

Table 2. SWCC and permeability function parameters

\begin{tabular}{|c|c|c|c|c|c|c|}
\hline Soil & $\boldsymbol{\theta}_{\mathbf{s}}$ & $\boldsymbol{a}$ & $\boldsymbol{n}$ & $\boldsymbol{m}$ & $\boldsymbol{k}_{\boldsymbol{s}}(\mathbf{m} / \mathbf{s})$ & $\boldsymbol{p}$ \\
\hline Clayey & 0.45 & 100 & 1 & 1 & $10^{-6}$ & 4 \\
\hline Sandy & 0.45 & 10 & 1 & 1 & $10^{-4}$ & 4 \\
\hline
\end{tabular}




\section{Results and discussion}

\subsection{Unsaturated slope stability analysis}

Unsaturated slope stability analysis was performed on Slope 1 and Slope 2 in three stages. First was the establishment of insitu stress for the slopes using SIGMA/W. Second was the application of 50 year RP rainfall $(22 \mathrm{~mm} / \mathrm{h}$ for $8 \mathrm{~h})$ using coupled stress - porewater pressure analysis using SIGMA/W. Finally, slope stability analyses were carried out using SLOPE/W for stress and pore-water pressure conditions during and after rainfall.



(a) Slope 1 (clayey soil)

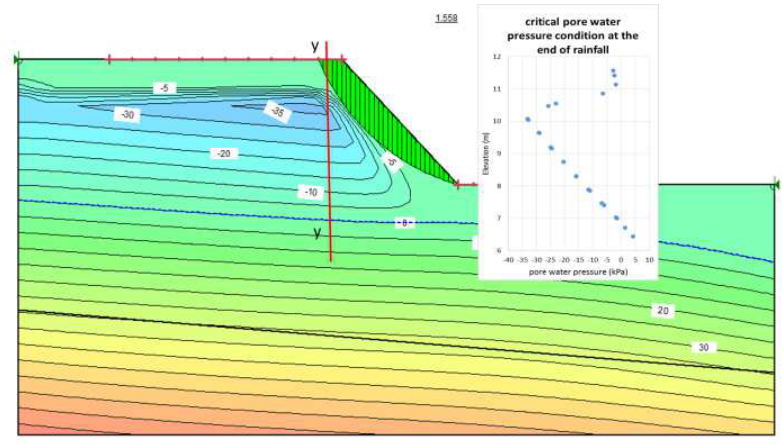

(b) Slope 2 (sandy soil)

Fig. 5. Critical pore water pressure variation due to rainfall infiltration and factor of safety for slope angle $45^{\circ}$

Analysis of Slope 1 (Clayey soil) for $70^{\circ}$ and $45^{\circ}$ slopes showed that the critical condition occurred $48 \mathrm{~h}$ and $72 \mathrm{~h}$ after rainfall respectively. In these times, the GWL has raised up to the GS. On the other hand, for Slope 2 (Sandy soil), the critical condition occurred at the end of rainfall and the GWL only raised slightly from the original location. The critical pore water pressure distribution along cross-sections y-y (in Fig. 3) are plotted in Fig. 5a and $5 \mathrm{~b}$ for Slope 1 and Slope 2 respectively. The pore-water pressure contours shown in Fig. 5 indicate the position of GWL at critical condition.

The FoS of Slope 1 and 2 with slope angle of $45^{\circ}$ and $70^{\circ}$ are plotted with time in in Figure $6 \mathrm{a}$ and $6 \mathrm{~b}$ respectively. It can be seen that the FoS of the slopes decreased during rainfall. For slope made of Sandy soil, the FoS reached minimum at the end of rainfall and increase again as the pore water pressure started to redistribute due to high coefficient of permeability. On the other hand, the FoS of the slope made of Clayey soil continued to decrease as the GWL continued to raise.
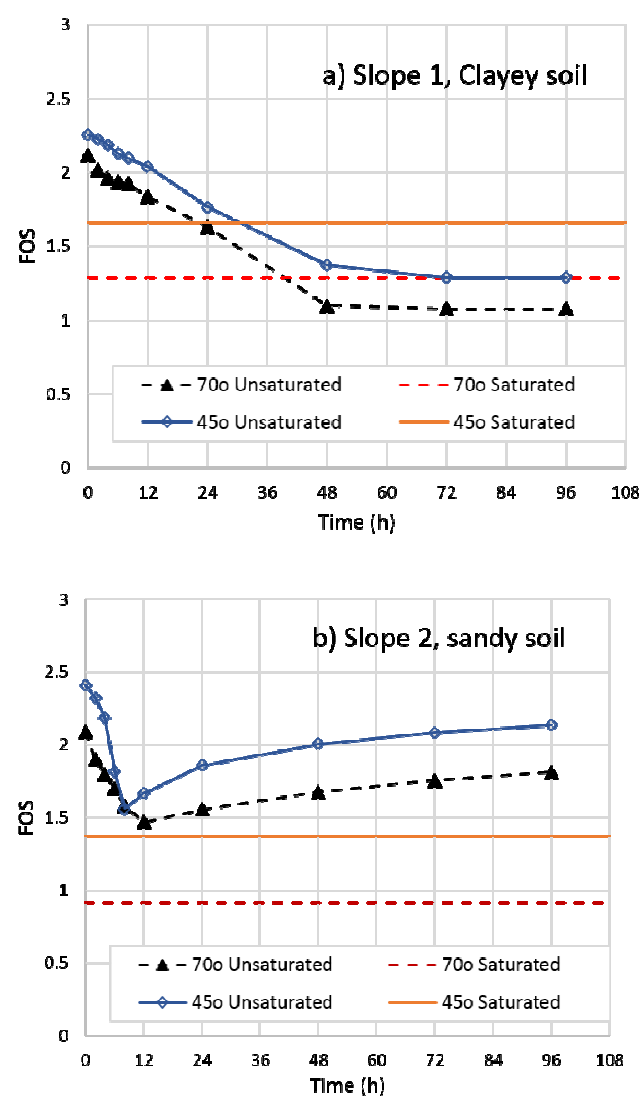

Fig. 6. Change in FoS with pore-water pressure and stress

\subsection{Conventional slope stability analysis}

The conventional stability analysis was carried out using SLOPE/W for Slope 1 and Slope 2 with original GWL as shown in Fig. 1 and critical GWL $1 \mathrm{~m}$ above the original GWL. Since both assumed GWL did not coincide with slip surface, the FoS obtained from both analyses are equal i.e. 1.661 and 1.285 for Slope 1 with slope angle $45^{\circ}$ and $70^{\circ}$ respectively. For Slope 2 with slope angle $45^{\circ}$ and $70^{\circ}$, the FoS are 1.372 and 0.917 respectively. These values are also plotted in Fig. 6.

Table 3 Summary of FoS obtained from different methods

\begin{tabular}{|c|c|c|c|c|c|}
\hline \multirow{2}{*}{ Slope } & \multicolumn{2}{|c|}{$\begin{array}{c}\text { Saturated/conventional } \\
\text { analysis for GWL }\end{array}$} & \multicolumn{2}{c|}{$\begin{array}{c}\text { Unsaturated } \\
\text { analysis }\end{array}$} \\
\cline { 2 - 6 } & $\begin{array}{c}\text { Origi } \\
\text { nal }\end{array}$ & $\begin{array}{c}\text { Raise } \\
\text { by 1 m }\end{array}$ & $\begin{array}{c}\text { at } \\
\text { GS }\end{array}$ & Initial & $\begin{array}{c}\text { Min FoS. } \\
\text { Time in } \\
\text { bracket }\end{array}$ \\
\hline $\begin{array}{c}\text { Clayey } \\
\text { Slope 1, } \\
45^{\circ}\end{array}$ & 1.661 & 1.661 & $\begin{array}{c}1.08 \\
\text { (n) }\end{array}$ & 2.54 & $\begin{array}{c}1.289 \\
(72 \mathrm{~h})\end{array}$ \\
\hline $\begin{array}{c}\text { Slope 1, } \\
70^{\circ}\end{array}$ & 1.285 & 1.285 & $\begin{array}{c}0.73 \\
2\end{array}$ & 2.12 & $\begin{array}{c}1.075 \\
(48 \mathrm{~h})\end{array}$ \\
\hline $\begin{array}{c}\text { Sandy } \\
\text { Slope 2, } \\
45^{\circ}\end{array}$ & 1.372 & 1.372 & NA & 2.409 & $1.668(8 \mathrm{~h})$ \\
\hline $\begin{array}{c}\text { Slope 2, } \\
70^{\circ}\end{array}$ & 0.917 & 0.917 & NA & 2.090 & $\begin{array}{c}1.458 \\
(12 \mathrm{~h})\end{array}$ \\
\hline
\end{tabular}


For slope 1, conventional slope stability analysis was also performed for condition where GWL as at the GS and the FoS were 1.083 and 0.732 for slope angle $45^{\circ}$ and $70^{\circ}$ respectively. Comparisons in the FoS obtained from different analyses are summarized in Table 3.

\subsection{Effect of suction on shear strength and FoS}

Slope stability analysis on four cases evaluated in this study indicated that unsaturated concept offer a more realistic estimate of the stability of slope. Rainfall infiltration does not only cause the raise in GWL as assumed in the conventional analysis, but also change in strength due to pore water pressure variation and deformation of soil.

The variation of shear strength with matric suction is illustrated in the following example for clayey soil. Assume a soil has a unit weight of $20 \mathrm{kN} / \mathrm{m}^{3}$; shear strength parameters of $\mathrm{c}^{\prime}=10 \mathrm{kPa}$ and $\phi^{\prime}=26^{\circ}$ and $\phi^{\mathrm{b}}=$ $2 / 3 \phi^{\prime}=17^{\circ}$. Assuming the GWL is at $3 \mathrm{~m}$ depth, the hydrostatic shear strength at depth of $1 \mathrm{~m}$ based on Eq. (2) is equal to $25.9 \mathrm{kPa}$. If rainfall infiltration caused the GWL to rise to GS, then the shear strength decreased to $11.8 \mathrm{kPa}$. For the same case, Eq. (1) will give the initial shear strength of $19.7 \mathrm{kPa}$ and final shear strength of $14.9 \mathrm{kPa}$. This shows that use of Eq (2) is not only results in higher shear strength due to suction but could also results in lower shear strength; hence lower factor of safety of the slope. Table 3 also shows that assuming GWL at GS for conventional stability analysis on Slope 1 gives a lower FoS as compared to the minimum FoS using unsaturated stability analysis even though the GWL was at the same position assumed in conventional analysis.

\section{Conclusions}

For slope made of coarse grained material, unsaturated stability analysis always give higher FOS than conventional analysis. The most critical condition is achieved a while after the end of rainfall.

For cases of delayed failure of slope made of clayey soil, unsaturated stability analysis could be more critical as compared to conventional analysis considering GWL raises about $1 \mathrm{~m}$ from original position (current practice). Conventional slope stability analysis using GWL coincide with GS give lowest FoS, however this consideration is over-conservative and not realistic, especially for sandy material whereby the effect of rainfall on GWL is minimum.

Unsaturated stability analysis of slope is a more realistic approach because it considers the actual GWL position as well as the change in shear strength due to deformation and variation of pore-water pressure variation.

The first author would like to thank Er. Lim Shiyi for discussion on state of practice on slope design in Singapore.

\section{References}

1. D.G.Fredlund, H. Rahardjo, Soil mechanics for unsaturated soils (John-Wiley \& Sons Inc. New York, 1993)

2. A. Kassim, N. Gofar, N.Mokhtar, M.L. Lee,Proc. international conference on slope Malaysia,1-12, 2006.

3. H. Rahardjo, A. Satyanaga, E.C. Leong, Y.S. Ng, ASCEJournal of Geotechnical and Geoenvironmental Engineering, 136(11), 15551564(2010)

4. J.M. Duncan, ASCE Journal of Geotechnical Engineering, 122(7) 577-596(1996)

5. H. Jitno, N. Gofar,Malaysian Journal of Civil Engineering. 17 (1) 1-12(2005)

6. H. Khabbaz, B. Fatahi, C. Nucifora, Proceedings of the 11th Australia New Zealand Conference on Geomechanics (ANZ 2012) 1293-1298(2012)

7. S.G. Goh, H. Rahardjo, E.C. Leong, ASCE Journal of Geotechnical and Geo-environmental Engineering. 136(4) 594-606(2010)

8. P.R. Vaughan, H.J. Walbancke, Géotechnique 23(4) 531-539(1973)

9. E. Conte, A. Troncone, Geotechnique 62(1) 8791(2012)

10. Geo-Slope International Ltd. SIGMA/W Stress deformation modelling. Calgary, Alberta, Canada (2012a).

11. Geo-Slope International Ltd. SLOPE/W for Slope Stability Analysis. Calgary, Alberta, Canada (2012b).

12. D.G.Fredlund, N.A. Morgenstern, R.A. Widger,Canadian Geotechnical Journal, 15, 3131321(1978)

13. A.S. Muntohar, Proc. 10th Indonesian Geotechnical Conf. and 19th Annual Scientific Meeting (2015)

14. E.C. Leong, H. Rahardjo, S.K. Tang, Proc. International Workshop on Characterization and Engineering Properties of Natural Soils. Vol. 2. 1279-1304(2002)

15. H. Rahardjo, F. Melinda, E.C. Leong, R.B. Rezaur, Stiffness of a Compacted Soil. Engineering geology. 120, 60-67(2011)

16. Public Utilities Board. Code of practice on surface water drainage. Singapore Drainage Department (2009)

17. Q. Zhang, J. He, A.M. Hee, The IES Journal Part A: Civil \& Structural Engineering, 5(1)62-64(2012)

18. H. Rahardjo, T.H. Ong, R.B. Rezaur, E.C. Leong, ASCE Journal of Geotechnical and Geoenvironmental Engineering, 133(12)15321543(2007)

19. D.G. Fredlund, A. Xing, Canadian Geotechnical Journal. 31(3) 521-532(1998)

20. E.C. Leong, H. Rahardjo, ASCE Journal of Geotechnical and Geo-environmental Engineering. 123(12) 1118-1126(1997) 